22 Duerr RH, Taylor KD, Brant SR, et al. A genome-wide association study identifies IL23R as an inflammatory bowel disease gene. Science 2006:314:1461-3.

23 Yamazaki K, McGovern D, Ragoussis J, et al. Single nucleotide polymorphisms in TNFSF15 confer susceptibility to Crohn's disease. Hum Mol Genet 2005; 14:3499-506.

24 Hampe J, Franke A, Rosenstiel P, et al. A genome-wide association scan of nonsynonymous SNPs identifies a susceptibility variant for Crohn disease in ATG16L1. Nat Genet 2007;29:207-11.

25 Li M, Atmaca-Sonmez P, Othman M, et al. CFH haplotypes without the $\mathrm{Y} 402 \mathrm{H}$ coding variant show strong association with susceptibility to age-related macular degeneration. Nat Genet 2006;38:1049-54.

26 Ahmad T, Armuzzi A, Bunce M, et al. The molecular classification of the clinical manifestations of Crohn's disease. Gastroenterology 2002; 122:854-66.

27 Cho JH, Nicolae DL, Gold LH, et al. Identification of novel susceptibility loci for inflammatory bowel disease on chromosomes $1 p, 3 q$, and $4 q$ : evidence for epistasis between Ip and IBDI. Proc Natl Acad Sci USA 1998;95:7502-7.
28 McGovern DP, Butler H, Ahmad T, et al. TUCAN (CARD8) genetic variants and inflammatory bowel disease. Gastroenterology 2006;131:1190-6.

29 Kobayashi KS, Chamaillard M, Ogura Y, et al. Nod2-dependent regulation of innate and adaptive immunity in the intestinal tract. Science 2005;307:731-4.

30 Watanabe T, Kitani A, Murray PJ, et al. NOD2 is a negative regulator of Toll-like receptor 2-mediated T helper type 1 responses. Nat Immunol 2004:5:800-8.

31 Wehkamp J, Harder J, Weichenthal M, et al. NOD2 (CARD15) mutations in Crohn's disease are associated with diminished mucosal alpha-defensin expression. Gut 2004;53:1658-64.

32 Negoro K, McGovern DP, Kinouchi Y, et al. Analysis of the IBD5 locus and potential gene-gene interactions in Crohn's disease. Gut 2003;52:541-6.

33 Sugimura M, Kinouchi Y, Takahashi S, et al. CARD15/NOD2 mutational analysis in Japanese patients with Crohn's disease. Clin Genet 2003:63:160-2.

34 Mannon PJ, Fuss I, Hornung R, et al. Anti-interleukin-12 P40 antibody treats active Crohn's disease. Gut 2004;53(Suppl IV):A48.

35 Happel KI, Dubin PJ, Zheng M, et al. Divergent roles of IL-23 and IL-12 in host defense against Klebsiella pneumoniae. J Exp Med 2005;202:761-9.

\title{
EDITOR'S QUIZ: GI SNAPSHOT
}

\section{Multiple liver lesions in a smoker}

\section{Clinical presentation}

A 39-year-old female smoker presented to the gastrointestinal unit with a 6-month history of increasing right upper quadrant pain, abdominal distension, nausea and anorexia. There was a history of dysmenorrhoea but no bowel disturbance. There was no medical history of note.

On examination, the abdomen was distended with right upper quadrant tenderness. Investigations showed a normal full blood count and normal renal and liver biochemistry. Inflammatory and tumour markers were not elevated. An

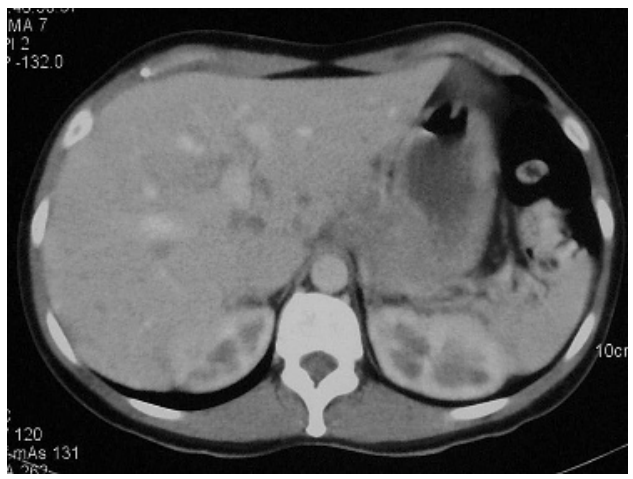

Figure 1 CT scan of the abdomen.

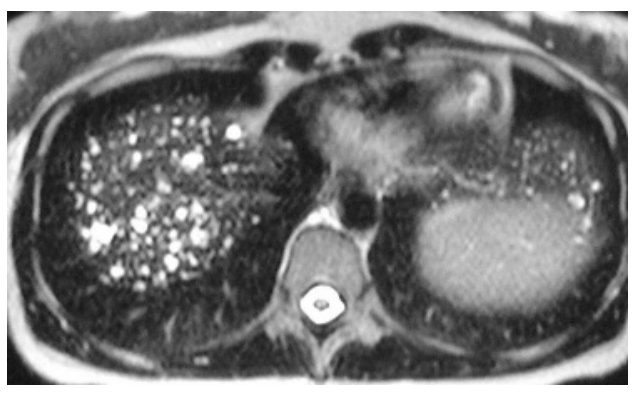

Figure 2 Axial T2-weighted MRI scan of the abdomen.
Robin Spiller, Editor

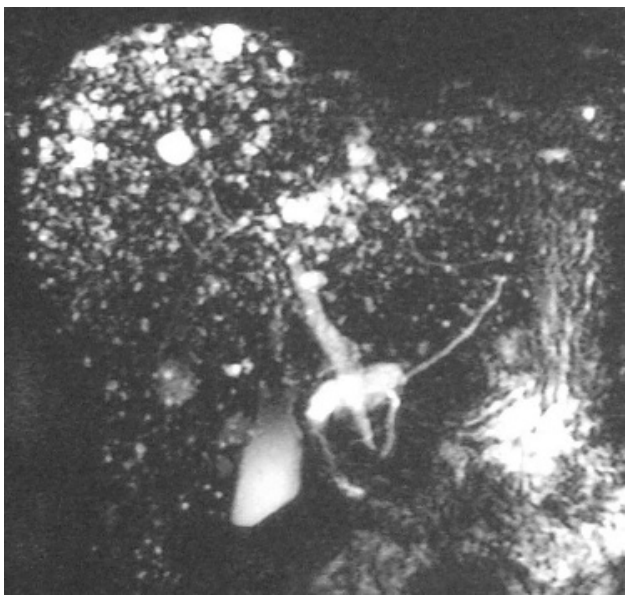

Figure 3 Coronal T2-weighted MRI scan of the liver.

abdominal ultrasound identified an enlarged liver with coarse echo texture and several focal abnormalities throughout both lobes. A CT scan of the abdomen showed multiple indeterminate areas of low attenuation within the liver (figure 1). MRI of the liver (figures 2,3) provided further characterisation.

\section{Question}

What is the diagnosis and what further investigation and follow-up is needed?

See page 1352 for answer

This case is submitted by:

J Sharkey, K R Palmer, I D R Arnott Gastrointestinal Unit, Western General Hospital, Edinburgh, UK S Glancy Department of Radiology, Western General Hospital, Edinburgh, UK

Correspondence to: Ian D R Arnott, Gastrointestinal Unit, Western General Hospital, Crewe Road, Edinburgh EH4 2XU, UK; ian.arnott@luht.scot.nhs.uk doi: $10.1136 /$ gut.2006.104893 